\title{
Evaluation of Erythrocyte Indices in Newborn According to Gestational Age
}

\author{
JESMEEN MORSHED ${ }^{1}$, MOHAMMAD KABIRUL ISLAM ${ }^{2}$, SANJOY KUMER DAY ${ }^{3}$, \\ MAHBUB MUTANABBI ${ }^{4}$, MOHAMMOD SHAHIDULLAH ${ }^{5}$
}

\begin{abstract}
Background: The normal hematological values in newborns differ significantly from those of infants, older children and adults. In our observation, the values of the newborn babies vary according to the gestational age. At birth the hemoglobin, hematocrit, mean corpuscular volume and mean corpuscular hemoglobin of term newborns are significantly higher than those of older infants and children, and in preterm newborns the differences are even more pronounced. The objective of this study is to evaluate the erythrocyte indices in preterm and term newborns at birth.
\end{abstract}

Methodology: This cross sectional study was conducted in the department of Neonatology in BSMMU from May 2014 to April 2015. A total of 86 newborns; 48 term and 38 preterm were included in the study. Newborns were divided into two groups- term group and preterm group. Erythrocyte indices: hemoglobin ( $\mathrm{Hb})$, hematocrit (Hct), red blood cell (RBC) count, mean corpuscular volume (MCV), mean corpuscular hemoglobin (MCH), mean corpuscular hemoglobin concentration $(\mathrm{MCHC})$ and red cell distribution width (RDW) were estimated from cord blood immediately after birth.

Results: Mean hemoglobin level in term group was $15.65 \pm 1.04 \mathrm{~g} / \mathrm{dl}$ and preterm group was $15.21 \pm 0.93 \mathrm{~g} / \mathrm{dl}$; this difference was statistically significant $(p<0.05)$. Mean hematocrit value was significantly higher in term group (47.27\%) than preterm group $(46.10 \%)(p<0.05)$. Mean $\mathrm{MCH}$ in term group was $34.49 \mathrm{pg}$ and preterm group was 35.83 pg; this difference was statistically significant $(p<0.05)$. Mean RBC count in term group was 4.47 million/cmm and preterm group was $4.35 \mathrm{million} / \mathrm{cmm}$. Mean MCV was higher in preterm group (107.70 fl) than term group (104.58 fl): Mean $\mathrm{MCHC}$ was higher in preterm group (33.34g/dl) than term group (33.0g/dl); Mean $R D W$ in term group was $18.18 \%$ and in preterm group was $18.58 \%$. These differences were not statistically significant ( $p>0.05)$.

Conclusion: This study concluded that erythrocyte indices of all newborns are not same; these differ according to gestational age.

Key words: Erythrocyte Indices, Newborn, Gestational age

\section{Introduction}

The normal hematological values in newborns differ significantly from those of infants, older children and adult. Quantitative and qualitative differences are

1. Medical Officer, Department of Paediatrics, BSMMU, Dhaka

2. Resident Physician, 250 Bed General Hospital, Noakhali

3. Associate Professor, Department of Neonatology, BSMMU, Dhaka

4. Associate Professor, Department of Paediatrics, BSMMU, Dhaka

5. Professor \& Chairman, Department of Neonatology, BSMMU, Dhaka

Correspondence: Dr. Jesmeen Morshed, Medical Officer, Department of Paediatrics, BSMMU, Dhaka. Mobile: +8801711150119; E-mail: jesm32@gmail.com

Received: 21 April 2018

Accepted: 21 June 2018 present at birth as a reflection of the developmental changes during fetal hematopoiesis. At birth the hemoglobin, hematocrit, RBC count, mean corpuscular volume and mean corpuscular hemoglobin of term newborns are significantly higher than those of older infants and children, and in preterm newborns the differences are even more pronounced ${ }^{1}$.

Hemoglobin concentrations gradually rise with increasing gestational age. At 10 weeks of gestation, the average hemoglobin is approximately $10.9 \mathrm{~g} / \mathrm{dL}^{1}$. By 22 to 24 weeks of gestation, fetal hemoglobin 
values reach approximately $12 \mathrm{~g} / \mathrm{dL}$, and by 30 weeks the hemoglobin concentrations is 13 to $14 \mathrm{~g} / \mathrm{dL}$. At term the average hemoglobin concentration is approximately 16 to $18 \mathrm{~g} / \mathrm{dL}$. Hematocrits increase from $30 \%$ to $40 \%$ during the second trimester and continue to increase over the latter part of the third trimester. Term hematocrits range from $50 \%$ to $63 \%$, with some variability due to delayed clamping of the umbilical cord. Circulating RBC concentrations gradually increase during the second and third trimesters. At term, RBC concentrations range from 5.0 to $5.5 \times 10^{6} / \mathrm{iL}^{2}$.

The fetal Mean Corpuscular Volume (MCV), progressively decreases with advanced gestational age specially in second and third trimesters. MCV is greater than $180 \mathrm{fL}$ in the embryo, falls to 130 to 140 $\mathrm{fL}$ by mid gestation, and decreases 105 to $115 \mathrm{fL}$ by the end of pregnancy. MCV of preterm infants decline quickly after birth and the postpartum changes in MCV appear to be related to chronological age rather than post conceptional age. The fetal Mean Corpuscular Hemoglobin ( $\mathrm{MCH}$ ), progressively decreases during second and third trimesters from $40 \pm 2 \mathrm{pg}$ in 25 weeks of gestation to $36 \pm 2 \mathrm{pg}$ at 40 weeks of gestation. Mean Corpuscular Hemoglobin Concentration $(\mathrm{MCHC})$ do not change appreciably with gestational age; it is approximately $34 \pm 1 \mathrm{~g} / \mathrm{dL}^{3}$ and remains relatively constant from birth to adulthood. MCHC ranges between 31 to $34 \mathrm{~g} / \mathrm{dL}$ during the newborn period. The Red cell Distribution Width (RDW) reflects the variation in RBC size. A more heterogeneous RBC population will be reflected by a larger RDW. Because immature cells are larger than older RBCs, an infant with active erythropoiesis will have an elevated RDW. The reference range for RDW is from $11 \%$ to $15 \%$ but varies with the instrument used ${ }^{4}$. In term infants, improved oxygenation after birth results in significantly decreased erythrocyte production, reflecting a natural adaptation to the extra-uterine environment.

Globally every year, an estimated 15 million babies are born preterm (before 37 completed weeks of gestation), and this number is rising ${ }^{5}$. In Bangladesh among all live births, $22.3 \%$ were delivered prior to 37 weeks of gestation (i.e. preterm) ${ }^{6}$. Preterm and small for gestational age (SGA) newborns are at risk of developing anaemia due to decreased intrauterine accretion of iron. Iron deûciency in infancy is associated with neurodevelopmental deûcits, delayed maturation of the auditory brainstem response and abnormalities of memory and behavior. Iron supplementation is required specially in preterm newborns. Therefore, the study was designed to evaluate the difference in cord blood erythrocyte indices between preterm and term newborns.

In Bangladesh there is scarcity of studies examining erythrocyte indices in newborns. So, purpose of this study was to evaluate erythrocyte indices in different subgroups of newborns. Information obtained from this study will help the clinicians and researchers future research work and management of newborns.

\section{Method:}

This study was carried out in the department of neonatology, BSMMU, Dhaka, Bangladesh over one year (May 2014 to April 2015). Total 86 newborns delivered normally or by cesarean section in BSMMU were selected into two groups-

Term newborns group (Gestational age $\geq 37$ and d" 42 weeks) consisting 43 newborn and

Preterm newborns group (Gestational age $<37$ weeks) consisting 38 newborn

Objective: The objective of the study was

- to measure the erythrocyte indices in preterm and term newborns at birth

- to compare the difference of erythrocyte indices between preterm and term newborns at birth to find out whether there is any significant difference.

Inclusion criteria: newborns delivered vaginally or by cesarean section in BSMMU were selected into two groups.

\section{Exclusion criteria}

Newborns with any major congenital anomaly, Severe perinatal complications or low APGAR scores $(<7)$ within the first five minutes of birth, Large for gestational age (birth weight $>90^{\text {th }}$ percentile), Multiple births, Baby of Rh-negative mother were excluded.

\section{Study Procedure:}

After getting the Institutional Review Board Clearance (IRB), written consent was taken from the parents/ 
legal guardians of newborns before enrollment of their babies in the study. After enrollment details of maternal and perinatal information were collected from maternal medical records and history taking. All newborns were examined in the first day of life. Gestational age was determined as completed weeks and assessed by last menstrual period (LMP), ultrasound and new Ballard scoring system.

Weights of newborns were taken by digital weighing machine (SALTER digital weighing machine) with an error of $\pm 5 \mathrm{gm}$. Length was measured by infanto-meter; occipital frontal circumference (OFC) was measured by nonstretching measuring tape. Anthropometric values were plotted on the growth chart. All informations were recorded for each newborn with a predesigned questionnaire. The newborns were divided into two groups- term newborns group and preterm newborns group.

Two (2) ml blood was collected from umbilical cord by $5 \mathrm{ml}$ disposable syringe immediately after birth in operation theater room or labor room of Obstetrics \& Gynaecology department of BSMMU. After collection, cord blood was sent in an EDTA containing tube to clinical pathology department of BSMMU within 30 minutes for examination of erythrocyte indices: hemoglobin $(\mathrm{Hb})$, hematocrit (Hct), red blood cell (RBC) count, mean corpuscular volume (MCV), mean corpuscular hemoglobin $(\mathrm{MCH})$, mean corpuscular hemoglobin concentration $(\mathrm{MCHC})$, red cell distribution width (RDW). Parameters were assessed by using fully automated blood cell counter (SYSMEX 4000i) and then checked manually by qualified senior clinical pathologist.

Data were stored and analyzed with standard computer software (SPSS 15). Student's t-test were done according to the nature of the data. Probability value of $<0.05$ was considered statistically significant.

\section{Results}

Over a 12 months period of study, total 86 newborns were enrolled for this study; 48 were term newborns and 38 were preterm newborns. Among the newborns male were 40 and female were 46 . Male to female ratio was $1: 1.15$
Table-I

Erythrocyte Indices in Term and Preterm Groups $(n=86)$

\begin{tabular}{lccc}
\hline $\begin{array}{l}\text { Erythrocyte } \\
\text { indices }\end{array}$ & $\begin{array}{c}\text { Term } \\
(\mathrm{n}=48) \\
\text { Mean } \pm \text { SD }\end{array}$ & $\begin{array}{c}\text { Preterm } \\
(\mathrm{n}=38) \\
\text { Mean } \pm \text { SD }\end{array}$ & $\begin{array}{c}\mathrm{P} \\
\text { value* }\end{array}$ \\
\hline Hemoglobin (g/dl) $)$ & $15.65 \pm 1.04$ & $15.21 \pm 0.93$ & 0.044 \\
Hematocrit $(\%)$ & $47.27 \pm 2.43$ & $46.10 \pm 3.01$ & 0.049 \\
RBC count & $4.47 \pm 0.49$ & $4.35 \pm 0.70$ & 0.323 \\
(million/cmm) & & & \\
MCV (fl) & $104.58 \pm 6.17$ & $107.70 \pm 9.20$ & 0.064 \\
MCH (pg) & $34.49 \pm 1.82$ & $35.83 \pm 2.95$ & 0.011 \\
MCHC (g/dl) & $33.00 \pm 1.06$ & $33.34 \pm 1.36$ & 0.190 \\
RDW (\%) & $18.18 \pm 2.18$ & $18.58 \pm 2.21$ & 0.407 \\
\hline
\end{tabular}

* Unpaired t-test was done to measure the level of significance

Table I shows that mean hemoglobin level in term group was $15.65 \mathrm{~g} / \mathrm{dl}$ and preterm group was $15.21 \mathrm{~g} /$ $\mathrm{dl}$; this difference was statistically significant $(\mathrm{p}<0.05)$. Mean hematocrit value was significantly higher in term group $(47.27 \%)$ than preterm group $(46.10 \%)$ $(p<0.05)$.Mean $\mathrm{MCH}$ in term group was $34.49 \mathrm{pg}$ and preterm group was $35.83 \mathrm{pg}$; this difference was statistically significant $(p<0.05)$. Mean RBC count in term group was 4.47 million/cmm and preterm group was 4.35 million $/ \mathrm{cmm}$; this difference was statistically not significant $(p>0.05)$. Mean MCV was higher in preterm group (107.70 fl) than term group (104.58 $\mathrm{fl})$ : Mean MCHC was higher in preterm group $(33.34 \mathrm{~g} /$ dl) than term group $(33.0 \mathrm{~g} / \mathrm{dl})$; Mean RDW in term group was $18.18 \%$ and in preterm group was $18.58 \%$. These differences were not statistically significant $(p>0.05)$.

\section{Discussion}

The normal hematological values in newborns differ significantly from those of infants and older children. At birth, the hemoglobin, hematocrit, RBC count, mean corpuscular volume and mean corpuscular hemoglobin of term newborns are significantly different from those of infant or older children, and in preterm newborns the differences are even more pronounced ${ }^{9}$. Erythrocyte indices also significantly differ in term and preterm newborns.

In this study, we observed that hemoglobin and hematocrit values of term newborns were significantly 
higher than preterm newborns $(p<0.05)$. We also found $\mathrm{MCH}$ values of preterm newborns were significantly higher than term newborns $(p<0.05)$. Findings of this study are consistent with the findings of previous study done by Nunes et al, $2010^{7}$. They also found that preterm newborns presented the higher mean value for $\mathrm{MCH}^{7}$.

In our study MCV, MCHC and RDW of preterm newborns were also higher than term newborns but these difference were not statistically significant ( $p>0.05)$. We also found RBC count higher in term newborns than preterm newborns but it was statistically not significant ( $p>0.05)$. Another study done by Noguera et al in Rosario, Argentina showed mean values of RBC count were higher in term newborns than that of preterm newborns. They also found preterm newborns showed higher mean value of $\mathrm{MCV}, \mathrm{MCH}$ than term baby ${ }^{8}$. That is also consistent with our findings. Inspite of higher $\mathrm{MCV}$ and $\mathrm{MCH}$ values in preterm, the lower hemoglobin and haematocrit values in preterm newborns might be due to lower RBC count. These characteristics of preterm newborns are related to physiologic immaturity of the erythropoietic system.

In the present study, we evaluated another parameter red cell distribution width (RDW), which was not evaluated in most of other studies. We found, mean RDW was higher in preterm newborns than term newborns $18.58 \pm 2.21 \mathrm{gm} / \mathrm{dl}$ and $18.18 \pm 2.18 \mathrm{gm} / \mathrm{dl}$ respectively ; although this difference was not statistically significant $(p>0.05)$ but it was consistent with other study ${ }^{7}$.

We compared our findings with term newborns as a reference standard (Table-1) and also, to those obtained in others studies that had evaluated hematological parameters in cord blood. We also observed that our hemoglobin values were similar with those usually used as reference standards in neonatology ${ }^{2}$.

Our results regarding $\mathrm{MCV}$ values were higher to those reported in some study ${ }^{7}$, and lower than those observed by others ${ }^{8}$.

Probable explanation for the observed differences may due to timing of umbilical cord clamping after birth, which could affect the RBC parameters of neonates ${ }^{9}$. Another explanation may be that compared with others study population groups were of different ethnic background.

\section{Conclusion}

This study concluded that erythrocyte indices of all newborns are not same; these differ according to gestational age. The difference of $\mathrm{Hb}, \mathrm{Hct}, \mathrm{MCH}$ are significant in preterm and term newborn. These informations may help the neonatologists to make a pre-emptive plan for managing preterm babies for anaemia and other haematological problems.

\section{References}

1. Eileen K. and Eman S. Late vs Early Clamping of the Umbilical Cord in Full-term Neonates, Systematic Review and Meta-analysis of Controlled Trials, The Journal of American Medical Association, 2007; 297(11): 1241-52.

2. Alarc'on P. and Werner E. Neonatal Hematology. First edition. New York: Cambridge University Press.2005.

3. Christensen RD, Jopling J, Henry E, and Wiedmeie SE. The Erythrocyte Indices of Neonates, Deûned Using Data from Over 12000 Patients in a Multihospital Health Care System, Journal of Perinatology, 2008; 28: 24-28.

4. Alemu Y, Atomsa A, and Sahlemariam Z. Ethiopia Public Health Training Initiative, Ethiopia.2006.

5. Wintrobe MM. Blood, Pure and Eloquent. NewYork: McGraw-Hill .1980. (WHO, (2017) int/ mediacentre / factsheets / fs 363 / en, $N^{\circ} 363$.) Accessed on 15 March 2018.

6. Shah R, Mullany LC, Darmstadt GL, Mannan I, Rahaman SM, Talukdar RR, Applegate JA, Begum N, Mitra D, and Arifeen SE. 'Incidence and Risk Factors of Preterm Birth in a Rural Bangladeshi Cohort', Biomedcentral Pediatrics, 2014;14: 112.

7. Nunes MF, Oliveira AM, Conceicao SM, and Medrado FE. Erythrocyte Indices and Serum Ferritin in Newborns, Brazilian Journal of Hematology and Hemotherapy 2010; 32: 36570.

8. Noguera N, Detarsio G, Perez SM, Bragos IM, Lanza O, Rodriguez JH, Acosta I, Davoli R, and Milani AC. Hematologic Study of Newborn Umbilical Cord Blood, Medicina (B Aires) 1999; 59: 446-8.

9. Maria AP. Issues in Neonatal Cellular Analysis, American Journal of Clinical Pathology 2009; 131: $560-73$.

10. Timothy CE. and Dietrich J. The Red Cell Distribution Width, The Journal of Emergency Medicine 1991; 9: 71-4. 